Discussion.

The Chairman then expressed the thanks of the meeting for the charming paper they had just heard. He thought the notion that a liking for club surroundings was limited to men no longer held good. Ladies' clubs in London presented to him no features not present in men's clubs, and he felt sure the house and its surroundings were well suited to the needs of both men and women. The place breathed homeliness and restfulness, and was satisfying to one's artistic sense. The discussion was then continued by Drs. Stilwell, Umney, Sergenat, Rice and Norman.

Afterwards members and other guests were entertained to tea.

\title{
SOUTH-WESTERN DIVISION.
}

The Autumn Meeting of the Division was held by kind invitation of the Committee of Visitors and Dr. J. McGarvey at the County Mental Hospital, Wells, Somerset, on Thursday, October 24, 1929.

Fourteen members were present and three visitors (Alderman R. A. Hobhouse, Chairman of the Visiting Committee, and Drs. Coleman and Simpson).

Sir John Macpherson was voted to the Chair.

The minutes of the last meeting were confirmed and signed.

Apologies for absence were received from the President, Ex-President, Dr. Soutar, Divisional Chairman, and other members.

Dr. W. Starkey was nominated as Hon. Divisional Secretary, and Drs. Barton White and J. McGarvey as Representative Members of Council for the year 1930-31.

The following was unanimously elected an ordinary member of the Association:

David Sheridan Spence, B.A., M.B., B.Ch.Dubl., Assistant Medical Officer, City and County Mental Hospital, Burghill, Hereford. Proposed by Drs. J. G. Smith, D. M. Cox and W. Starkey.

An invitation from Dr. S. Edgar Martin to hold the Spring Meeting on Thursday, April 24, 1930, at Hume Towers, Bournemouth, was gratefully accepted.

The remainder of the meeting was of a purely clinical character, and several interesting and instructive cases were shown and discussed by the medical staff of the Hospital.

Dr. MCGARVEY showed two female idiots, members of a family of mental defectives, in which there was a history of chronic lead poisoning in the motherthe source of the poison being traced to the water supply derived from a well on the site of an ancient lead mine dating from Roman times.

Dr. A. Darlington showed a woman with signs pointing to a lesion in the pons, and discussed the differential diagnosis between tumour and a vascular lesion.

Dr. D. Menzies showed a male case of cerebral syphilis with unusual symptoms, and dealt with the distinction between meningo-vascular syphilis and general paresis. A discussion ensued, in which the Chairman and Drs. J. M. Rutherford, E. Barton White, G. W. T. H. Fleming and others took part.

During the morning members visited the Hospital and inspected the various departments. They were most hospitably entertained to lunch, and after the meeting Dr. and Mrs. McGarvey kindly provided tea.

The extremely unfavourable weather conditions prevented several members who had intended to be present from reaching the Hospital.

NORTHERN AND MIDLAND DIVISION.

The Autumn Merting of the Division was held, by the courtesy of Dr. A. T. W. Forrester, at Warwick County Mental Hospital, Hatton, near Warwick, on Thursday, October 24, 1929.

There were twenty-four members present.

During the forenoon members were shown over the hospital, and were afterwards entertained to lunch. 
Dr. Gilmour proposed a vote of thanks to Dr. Forrester and the Visiting Committee of the Hospital for their kind hospitality. This was carried by acclamation, and Sir Michael Lakin, Bart., Chairman of the Committee, responded.

Dr. J. R. Gilmour, Chairman of the Division, presided.

The minutes of the previous meeting were read and confirmed, and apologies for absence were communicated.

It was resolved that in view of the appointment of a Divisional Chairman, the election of a Divisional Committee of Management was not necessary.

The following members were elected to serve on the Divisional Clinical Com. mittee: Prof J. Shaw Bolton, Drs. M. A. Archdale, J. Bain, H. Dove Cormac, A. T. W. Forrester and Neil MacLeod.

It was resolved to accept Dr. Barkas's invitation to hold the Spring Meeting in 1930 at The Lawn, Lincoln, the Secretary being instructed to make inquiries regarding the most generally convenient day of the last week of April.

The following resolution of Council of July 9th, 1929, was considered :

"That the Council approves the principle of the wearing of a badge of

office by the Chairman of a Division, when presiding over a Divisional Meeting, and on other suitable occasions."

And it was resolved :

"That this Division is not desirous that its Chairman should wear a Badge of Office."

The following Council minute, dated February 16, 1928, was read in reply to a question (see Autumn Meeting, 1927) :

"The following resolution by the Northern and Midland Division was considered: "That the date of the Autumn Nursing Examination be altered to the last Monday in November and the first Monday in December.' Dr. Soutar moved and Dr. James seconded that no alteration be made. This was carried."

Dr. Florence M. Gamble read a most interesting paper which the Chairman described as " a monument of industry," entitled "Some Laboratory Findings in the Routine Investigation of Acute Admissions."

Dr. H. Dove Corsac introduced for discussion the subject of "The Training and Examination of Mental Nurses."

He referred to various changes which he thought might with advantage be effected.

He pointed out that the number of candidates had grown very considerably, and suggested that as the proportion of entries from English and Welsh mental hospitals, as compared with those from Scotland and Ireland, was about 3 to 2, two additional examiners for England should be appointed, thus making one for each Division. The members present unanimously agreed with this view.

Dr. Dove Cormac also referred to the fact that in the last final examination the question paper contained only two questions which could be described as bearing on mental disorders and mental nursing, whereas the other six dealt with physical diseases and general nursing. He thought that, as the Certificate granted to our nurses was for proficiency in mental nursing, the proportion of questions on that subject should be as 2 to $x$.

On a vote being taken Io members were in favour of the suggestion, but I $_{3}$ considered that the questions set should be in the proportion of $50 \%$ mental and $50 \%$ general.

Dr. G. L. BRUNTon proposed that a return to the three-examination system be recommended. The motion was defeated by a majority.

Most of the members present took part in the discussion, and the view was generally expressed that the visiting examiner should be the chief examiner at both the preliminary and final examination of nurses. Dr. Dove Cormac was requested to convey the opinions of the meeting to the Education Committee.

Dr. Chevens outlined a scheme of work of a group of the Psychopathology SubCommittee on the Relationship of Heredity and Suicide, and invited criticisms and suggestions.

The painstaking work of Dr. Nicole, the Secretary of the Psychopathology SubCommittee, was referred to, and it was pointed put that the small group formed to undertake research into the psychopathic inheritance of suicidal cases was one of the many results of his energy in organization. 
A few relevant facts about suicide were then mentioned, its possible relation to the climacteric in both sexes remarked on, and a summary given of the mental condition of 50 cases of potential suicide recently examined at Parkside Mental Hospital.

Various theories of suicide were then noted, including Freud's and Hoch's, and it was pointed out that while these theories might account for the mechanism of the actual suicidal attempt, they did not explain the deeper factor-the reason for that mechanism.

The present group had been formed to try and discover if this deeper factor is related in any way to inherited mental characteristics.

A short summary of the scheme was then given, which fell under the following headings :

I. The mental state of the patient.

2. The physical state of the patient, classifying under ( $\mathrm{x}$ type of personality and (2) physical type.

3. The personal history of the patient.

4. The family history, paying special attention to such matters as types, evidence of psychopathic personalities, definite morbid symptoms, etc.

5. Correlation of (I), (2), (3) and (4).

6. Pooling of results by all the investigators for the purpose of joint consideration.

Suggestions as to various methods of work were referred to under each of these headings.

In conclusion, the reference of the Commissioners in their last Annual Report to the necessity of research into the subject of suicide was mentioned, and the value of co-operative work in this connection emphasized.

Dr. FORRESTER gave a most instructive and interesting demonstration of treatment of recent cases by means of Swedish drill and other varied and graded exercises, including country dancing. The patients wore suitable and pleasing costumes. The beneficial effect of the treatment was evident, and Dr. Forrester spoke of the very satisfactory results which he had obtained.

Members were afterwards very kindly entertained to tea by Mrs. Forrester.

\section{SCOTTISH DIVISION.}

The Autumn Merting of the Scottish Division was held at the Murray Royal Asylum, Perth, on Friday, November 15, 1929.

There were sixteen members present.

Dr. R. B. Campbell, Divisional Chairman, presided.

The minutes of the last Meeting were read, approved, and signed by the Chairman.

Apologies for absence were intimated from the President, Sir Arthur Rose,

Prof. G. M. Robertson, and Drs. Keay, Carre, Leggatt, Skeen, Henderson, Ivy

Mackenzie, McMillan, Hotchkis, Steele, Chislett, O'Flaherty, Connell, Fairbairn,

McLaren, Yellowlees, Dods Brown, McRae and Sturrock.

Dr. Douglas McRae was nominated for appointment as Divisional Chairman but Dr. Easterbrook explained that Dr. McRae was not desirous at present of holding office in the Division. Dr. Neil T. Kerr was thereupon nominated for the position of Divisional Chairman for 1930-31.

Drs. Neil T. Kerr and C. J. Shaw were nominated Representative Members of Council, and Dr. W. M. Buchanan Divisional Secretary for 1930-31.

The Divisional Standing Committee of Management was appointed as follows : The Chairman of the Division, the Representative Members of Council, the Nominated Member of Council, the Divisional Secretary and Dr. Aidan G. W. Thomson.

The following candidates were unanimously elected by ballot ordinary members of the Association:

Thomas Arthur Howard Munro, M.B., Ch.B.Edin., Dip. Psych., Assistant Physician (temporary), Royal Edinburgh Hospital for Mental and Nervous Disorders, Craig House, Edinburgh.

Proposed by Prof. G. M. Robertson, Drs. W. M. McAlister and D. S. Spence.

LXXVI. 